\title{
LOS DESAFÍOS DEL ARTE EN EL CONTEXTO DE LA EDUCACIÓN PÚBLICA ACTUAL
}

Federico Galende Pellegrini 


\section{FEDERICO GALENDE PELLEGRINI}

Cientista Político, Doctor en Filosofía, Director del Departamento de Teoría e Historia de las Artes de la Facultad de Artes de la Universidad de Chile. 


\section{LOS DESAFÍOS DEL ARTE EN EL CONTEXTO DE LA EDUCACIÓN PÚBLICA ACTUAL}

La pregunta por el rol del arte en el ámbito de la educación pública es un raro anexo a la condición del arte de todos los tiempos. En rigor, el arte nació anudado a la cuestión de lo público. Esto en virtud de que no tuvo su origen en la universidad, sino en las calles, y representa el modo de hacer de todos aquellos que, desde La República de Platón hasta nuestros días, fueron retirados o expulsados de la escena política. El motivo de esa expulsión reside en el hecho de que el artista ejerció desde siempre un tipo de práctica que venía a distorsionar lo que el poder esperaba del trabajo. Esto no significa que el artista no trabaje (el artista no sólo trabaja, sino que lo hace además dos veces, trabajando primero como cualquiera y trabajando, después, para dar a ese trabajo de cualquiera la singularidad de un arte); significa más bien que ejerce un tipo de práctica que aporta, a la privacidad relegada del trabajo, una cierta visibilidad: introduce en el espacio de lo común la idea de que todos somos capaces de más de una cosa, de realizar una tarea distinta a aquella a la que fuimos confinados.

En este sentido, lo que diferencia al artista del trabajador no es una capacidad mayor o menor para transformar la materia, sino la pertenencia a esferas sensibles que son depositarias de atenciones distintas. Dado que como dice Rancière la pobreza no se define por una relación de pereza con el trabajo, sino por la imposibilidad de escoger en qué fatigarse, un artista no es más que un trabajador que ha tenido la oportunidad de elegir su cansancio ${ }^{22}$. Es por esta elección relativamente libre que el arte constituye una promesa política libertaria: interviene en lo público instalando, sea cual sea su intención política, la idea de una comunidad no restringida a la distribución natural de roles y funciones, es decir, la idea de que cualquiera está capacitado para hacer algo distinto de aquello para lo que le han hecho creer que sirve de manera exclusiva. Por eso todo arte es público.

Pero es precisamente por esto, porque todo arte es constitutivamente público, que su estatus en el campo universitario resulta complejo, pues su práctica corresponde justamente a un modo de hacer que es heterogéneo a la especificidad de una formación. Este modo de hacer heterogéneo es de carácter experimental. Y alguien experimenta

22 Respecto de este punto, ver Jacques Rancière, La noche de los proletarios, Traducción y notas de Emilio Bernini y Enrique Biondini, Buenos Aires: Tinta Limón, 2010, p. 34. 
cuando usa libremente todas las capacidades de las que se vería privado si hubiese tenido que respetar el dictado de una teoría o un modelo de aprendizaje trazado de antemano. Es el principal dilema al que se debe atender cuando se nos propone el desafío de la enseñanza pública del arte. En la Universidad de Chile, el lugar que ha ocupado -y sigue ocupando- buena parte de la formación artística nos obliga a revisar tanto un modelo histórico de enseñanza como un enfoque sobre lo público.

Si comenzamos por lo segundo - esto es, por el enfoque que desde la formación artística universitaria se le ha dado a la cuestión de lo público-, concluiremos probablemente que la relación entre arte y educación no ha sido en Chile ni más ni menos remota que el origen mismo de la idea de nación. A diferencia de lo sucedido en la Europa ilustrada, donde esa idea surgió al interior de una mutación simbólica del imaginario colectivo, en América Latina la nación respondió desde un principio a la importación de una matriz que redujo la vida de los pueblos al marco rígido de un sistema político implantado. Ese encuadre tuvo que ver con el esfuerzo de una clase letrada por enmarcar la heterogeneidad de lo múltiple (la masa, la plebe) en el diagrama previo de una puesta en forma. Esta puesta en forma implicó, como todas las puestas en forma, un fuera de campo, un tipo de enfoque que segregó a la plebe mientras seleccionaba algunas de sus partes para anexarlas a una coreografía trazada por un programa de espiritualización ${ }^{23}$. En el origen de ese programa estuvieron presentes el espíritu de las leyes, el de las letras y el de la ilustratividad pictórica de la historia.

Lo anterior conduce a concebir la idea de nación como una idea en sí misma estética. Una idea estética es aquella que por medio de un programa de sensibilización de la "masa iletrada" define el espacio de lo visible en el que se desplegará de ahora en adelante la vida en común. La cría y reproducción de lo humano en el laboratorio de un espíritu trasplantado son las piezas claves que están a la base de esta educación de los sentidos. David Viñas mostró a propósito de esto cómo a partir de una generación en la que gravitaban Alberdi, Sarmiento o Andrés Bello, el escritor letrado obró como una especie de sacerdote y sus libros como pequeñas biblias $^{24}$. Esos sacerdotes letrados prosiguieron una tarea que habitaba ya en la punta del ovillo de la conquista y que había consistido en el sometimiento de los idolos por parte de las imágenes ${ }^{25}$.

Hay que considerar, por lo tanto, que en un contexto como este el concepto de educación pública del arte y de las letras estuvo constitutivamente asociado a

23 Para un tratamiento más extenso de este punto, ver Georges Didi-Huberman, Pueblos expuestos, pueblos figurantes, traducción de Horacio Pons, Buenos Aires: Manantial, 2014.

24 David Viñas plantea esta hipótesis en De Sarmiento a Cortázar, Buenos Aires: Siglo XX, 1974.

25 Respecto de este punto, ver Sergei Gruzinski, México: FCE, 1990. 
un plan de domesticación y alfabetización de la masa. Si las humanidades fueron el instrumento central de ese plan, la universidad pública fue el prospecto del Estado civilizatorio en el que este plan se asentó. Esto no sucedió en cualquier época, sucedió en la época que siguió a la edad de la independencia de las naciones. Pero la época que siguió a la independencia de las naciones estuvo indirectamente marcada por la herencia de una transformación del estatuto de la estética en el contexto mismo de la Europa moderna. Esa transformación consistió en que la aisthesis, considerada hasta mediados del siglo XVIII como una ciencia del conocimiento inmediato ligada a la prueba del mundo por parte de los sentidos (lo más parecido al conocimiento del animal o de la criatura), adoptó una repentina dignidad filosófica y terminó por adquirir los créditos de una esfera autónoma. Fue entre 1751 y 1791 (de Baumgarten a Kant) que las formas múltiples del conocimiento sensorial obtuvieron una unidad: la de la estética como un espacio autónomo habitado por una comunidad del sentir.

El problema reside en que esa comunidad del sentir no extrajo su autonomía de la reunión espontánea del uso libre de los sentidos, sino al revés: fue el efecto de una modelación de los órganos sensoriales del animal humano por parte de la facultad de lo sensible. En otras palabras: el nacimiento de la época de la autonomía estética está marcada ella misma por un programa de domesticación de un sensorium que era anónimo o impersonal. Por eso Levinas define lo sensible como una "facultad egoísta" ${ }^{26}$. Es egoísta en la medida en que pertenece al reino del sujeto, a la ilusión del Yo soberano, al individuo que cree percibir en su conmoción una cualidad que le es propia. Si el concepto de lo bello en Kant vino a reforzar esta facultad egoísta (en parte porque lo bello es ese objeto que, habiéndose separado de la circulación, da la impresión de dedicarnos su mirada), el concepto de lo sublime llegó para contrapesar ese refuerzo: lo inconmensurable, lo magnánimo, lo irrepresentable someten al sujeto a su pequeñez o insignificancia. Terry Eagleton escribió: "La belleza apuntala al sujeto en el mismo sentido en que lo sublime le da su escarmiento y lo humilla"27. En ese aspecto no es un dato menor que la Analítica de lo bello y lo sublime de Kant haya precedido en apenas un par de décadas a la invención de la nación latinoamericana. Así, lo que precedió al modelo de nuestros estados nacionales fue una reconfiguración del humanismo articulada a la domesticación de los sentidos.

26 Emmanuel Levinas, La realidad y su sombra, traducción de Antonio Domínguez Leiva, Madrid: Trotta, 2001.

27 Terry Eagleton, La estética como ideología, Madrid: Trotta, 2006. 
Esto representa el motivo por el que la palabra "civilización" estuvo en Chile unida desde el principio no solo a una subsunción de la naturaleza en el paisaje a través del cuadro, sino también a una subordinación del corpus heterogéneo de la masa a la unidad de encuadre del sistema político. Doblegar la naturaleza "intratable" en la pictoricidad del paisaje funcionó así como cifra de un programa general de espiritualización de la plebe del que la Academia de Bellas Artes primero y después la universidad pública, fueron su conducto fundamental. De ahí que el modelo de enseñanza que primó en la Universidad de Chile fue el de una construcción de lo público desde la demanda de alfabetización del Estado. Esta demanda -de la que en ocasiones se sigue hablando actualmente- nutrió una concepción estética sobre lo público que terminó chocando con lo público entendido como una permanente reconfiguración de lo común en manos de la experimentación artística. De ahí en adelante, lo que es común al arte se divide a la vez entre una idea estética aplicada y una promesa libertaria que es inherente a su hacer.

La promesa libertaria de la que hablamos no tiene nada que ver con la tendencia histórica de las vanguardias a concientizar al espectador por medio de determinadas consignas visuales o con la tendencia a romper la autonomía estética en nombre de una disolución del arte en la vida (se diría que esos procedimientos están ellos mismos del lado obsesivo de la idea estética); por el contrario: tiene que ver con el arte entendido como un proceso al interior del cual los hombres comparten una práctica que los aleja del mundo dirigido. Si para la idea estética de República, la idea vanguardista de ruptura o la idea revolucionaria de utopía los hombres debían sumir su lucha singular en pos de una causa en común, para este nuevo modo de comprensión del arte lo que los hombres tienen en común es la lucha por un hacer que es diverso y singular.

Pese a haber asomado y desaparecido a lo largo de varias décadas, esta concepción del arte es la que parece haber estado por detrás de las movilizaciones del 2011, que irrumpieron en el espacio de lo común tensionando no solo la idea de lo público que subyace al modelo alfabetizador de la universidad letrada, sino también el poder que el artista de vanguardia y el intelectual crítico detentaron desde siempre en la dirección de los cambios de la realidad política. Que los temas de aquella agenda se concentraran prioritariamente en asuntos vinculados a la cuestión del lucro y la calidad de la educación pública, no quiere decir que no hayan impactado en la erosión de un modelo de enseñanza de las artes en la universidad.

Esto nos permite pasar al primer punto que nos planteábamos más arriba: el de la práctica de la enseñanza artística en el contexto (muy castigado o alicaído) de la universidad pública actual. Se podría partir por decir que en la medida en que ese modelo de enseñanza estuvo enfocado hacia lo público desde un concepto de arte muy apegado a la idea estética de nación (la idea de la ciudad letrada o espiritual), el 
problema del arte en cuanto tal derivó en una pérdida de su sentido más primigenio, consistente en ser simplemente un juego o un proceso en el que las capacidades humanas se expanden o ramifican sin obedecer a una meta predeterminada. Dicho en breve, el arte extravió su núcleo experimental en nombre de una finalidad ilustrativa.

El tema no es tan novedoso si se considera que fue el propio Joseph Kosuth quien en 1969 cerró una célebre conferencia que dictó en el auditorio de nuestra Facultad de Artes reparando en este punto. En esa ocasión Kosuth terminó su alocución señalando que "no se le puede ni enseñar ni decir jamás al estudiante qué es el arte, puesto que eso lo decidirá él" 28 . Su sugerencia, si entiendo bien, apuntaba al hecho de que cuando el arte no se ciñe a ser el medio del que la universidad se vale para transferir una idea estética de lo público postulada desde el espíritu letrado, se convierte en una pregunta abierta que pertenece a su contemporaneidad: todo lo que es arte puede a la vez no serlo. Esta pregunta transcurre al interior de un espacio universitario reflexivo en el que aquello que es el arte no depende ya de una sanción impuesta por el maestro, sino de un modo de hacer colectivo en permanente estado de redefinición.

Lo que particulariza este modo de hacer en el concierto de las facultades que forman parte de la universidad pública es una suspensión atípica que recae sobre el sistema de las profesiones, las competencias, los saberes finalizados y la investigación aplicada. Se trata de un desplazamiento respecto de la formación universitaria que halla en el hacer del arte un carácter performático. Ahora bien, ¿qué es lo performático? Lo performático es un modo de hacer que se vale de un conjunto de presupuestos que se verifican a sí mismos en la propia potencia de su despliegue. Desde esta perspectiva una obra, una teoría, un discurso, una producción visual determinada no son falsos o verdaderos; solo pueden ser interesantes.

Lo anterior es útil desde luego cuando se quiere diferenciar el tipo de formación que debiera impartirse en una facultad de artes en relación a la formación que es propia del campo de la investigación finalizada. El arte no tiene un fin, no persigue ningún fin, por lo que su lugar en la universidad es el de un espacio en que se crean presupuestos reflexivos que no responden a ningún axioma o imperativo que el saber teórico pueda situar por delante de la propia práctica humana. Esto no quiere decir que en lo relativo al arte la teoría sobre o esté de más; es al revés: la teoría deviene en el arte una práctica, pues está impedida de exhibir un horizonte que

28 "Painting versus Art versus Culture..." es el título de la conferencia que Kosuth leyó en la Universidad de Chile (dos años más tarde leyó la misma conferencia en el Cleveland Art Institute y en el Coventry College of Art, Inglaterra), versión digital www.plantarevista.com.ar. 
trascienda al despliegue de una potencia en la que ella misma se verifica. Lo que esto suscita es la idea del taller o del aula como espacio de una forma experimental que anudan a la producción visual y el discurso estético en un punto en común. Este punto en común reside en el hecho de que no hay práctica visual que no tenga consecuencias teóricas ni tampoco teorías que no tengan consecuencias visuales.

El presupuesto que a esto subyace fue definido por Rancière: le llamó "el presupuesto de la igualdad" 29 . Que la igualdad sea un presupuesto significa desde luego que no forma parte de un horizonte al que el estudiante accederá siguiendo los pasos que el maestro le impone día tras día, sino que es la base inextinguible de una inteligencia en común, una inteligencia indivisible de la que cada quien puede hacer uso. Esto es lo que se quiere decir cuando se plantea que la inteligencia es en realidad "una sierva de la voluntad". En el espacio singular del arte, la teoría y la práctica comparten esta inteligencia indivisible de la que hacen diversos usos. Pero estos usos no solo impactan en las relaciones de orden y subordinación que a la práctica y a la teoría se les quiere suponer, sino que además niegan toda relación de necesidad entre la actividad propia de un modo de hacer del arte y la supuesta pasividad de la contemplación estética.

Es en virtud de que la negación de esta relación mantiene en el espacio del arte una posición central o privilegiada que, en el seno de una facultad como la nuestra, el asunto requiere ser transportado especialmente a lo que sucede al interior de sus aulas o talleres. Lo que allí debiera primar es nada menos que la disipación de la lógica explicadora, una lógica que el escritor J.M. Coetzee satirizó en un pasaje notable de La vida de los animales ${ }^{30}$.

Allí se nos presenta el caso de Sultán, un simpático chimpancé que ha sido encerrado en la jaula de un laboratorio. El maestro científico lo ha confinado por un tiempo con el fin de someterlo a algunas pruebas. Las pruebas son todas estúpidas. Sultán tiene hambre, el suministro de alimentos, que hasta hace poco le llegaba, le llega ahora de manera esporádica o no le llega. El suministro de alimentos se ha interrumpido de forma extraña y ahora en cambio el maestro cruza un alambre sobre la jaula, a tres metros del suelo, de donde cuelga un racimo de plátanos. En la jaula hay tres cajones de madera, el maestro científico ha dado un portazo y se ha retirado. El maestro científico se ha retirado porque quiere que Sultán piense. Pero ¿qué es lo que debe pensar? Se supone que debe pensar dos cosas de las cuales solo una será "correcta", la que el maestro sancione. Lo que Sultán piensa,

29 Esto Jacques Rancière lo desarrolla fundamentalmente en El maestro ignorante, cinco lecciones sobre la emancipación intelectual, traducción de Nuria Estrach, Barcelona: Laertes, 2003.

30 er J.M. Coetzee, La vida de los animales, traducción de Miguel Martínez-Lage, Barcelona, Mondadori, 2001. 
por ejemplo, adopta de inmediato la forma de una pregunta: ¿Qué he hecho?, ¿por qué me quieren matar de hambre? Piensa que a lo mejor ha dejado de agradar a su cuidador, piensa que ha sido castigado por algo que desconoce o piensa que el maestro ha descuidado él mismo esos cajones, que han quedado abandonados en la jaula. No, ninguno de estos razonamientos es el correcto, porque el único razonamiento correcto es el que el maestro ha trazado de antemano para Sultán: él tiene que pensar cómo alcanzar los plátanos, para lo cual debe apilar los cajones e improvisar una pequeña torre sobre la que hacer equilibrio. Es lo que hace Sultán: apila los cajones, improvisa una torre, alcanza los plátanos. Y entonces entiende que el maestro ha comprendido que pudo resolver el asunto y pondrá punto final a este desafío de mal gusto. Pero el maestro no quiere poner punto final, no quiere cerrar el círculo de la explicación. Aunque Sultán ya ha dado con el razonamiento "correcto", sigue en deuda. El maestro se lo demuestra colgando esta vez los plátanos a más altura y dejando los mismos cajones pero llenos de piedras. Sultán debe pensar, pero ¿qué es lo que debe pensar? Se supone que lo que debe pensar es que el maestro está lleno de malicia, que ha llenado los cajones de piedra, que al parecer no le ha bastado con las molestias que ya le causó el día anterior. Pero ninguno de estos razonamientos es el correcto; lo correcto es que Sultán razone de modo tal que pueda acceder a esos plátanos, para lo cual debe vaciar pacientemente los cajones de todas esas piedras, apilarlos uno encima del otro, improvisar una torre y hacer nuevamente equilibrio sobre ella. Es lo que hace; al día siguiente la dificultad será aún mayor.

Lo que Coetzee nos muestra en este pasaje es cómo la complejidad del desafío impuesto por el orden explicador conduce al chimpancé a formular cada vez el pensamiento menos interesante. En lugar de pensar libremente, en lugar de dejar errar sus pensamientos por mundos de los que extraer nuevas asociaciones e imágenes, Sultán debe concentrarse en estrecharlos y dirigirlos solo a un propósito miserable: conseguir el alimento que necesita para sobrevivir.

Es lo que le interesa al orden explicador: no potenciar en cada quien las capacidades creativas con las que ya cuenta para salir de un atolladero, sino forjar una atmósfera que asegure la dependencia. En realidad se trata del típico caso de un orden según el cual el estudiante debe resignar lo que piensa por sí mismo en nombre de una razón que lo extorsiona. La extorsión de la razón opera aquí exactamente al revés que el presupuesto de igualdad que resulta inherente al presupuesto performático que es propio del arte, puesto que subordina la heterogeneidad del proceso a un resultado que ha sido puesto por delante y que debe ser alcanzado. La subordinación del proceso al resultado (que no es más que la subordinación de la igualdad como un presupuesto en común a la igualdad como un horizonte prometido por el saber del 
experto) es parte de un hábito que está en el origen del programa ilustrado de la universidad pública.

El problema de este programa es que en la época actual ha terminado por ser funcional a un modelo de Estado que se desliga del aporte infraestructural que es necesario para la experimentación estética, en parte porque la construcción de lo público desde el arte como dispositivo de sensibilización ha dejado de ser una prioridad. Lo que así tenemos en el campo de la educación artística es un modelo que se ha visto obligado a incorporar una serie de rutinas académicas que no guardan ninguna relación con la práctica experimental del arte y que lógicamente acaba por sumir a la Facultad de Artes en una clara situación de desventaja.

Una posibilidad distinta surge cuando lo que se recupera del hacer estético es su resistencia constitutiva al modelo del orden explicador. En este caso, el aula o el taller se transforman en un laboratorio experimental en el que estudiantes y profesores comparten la igualdad como un punto de partida en común, esto es: como un presupuesto que se verifica a sí mismo en la potencia comunitaria de su despliegue, y no como un horizonte en el que se promete la consumación futura de una idea sensible.

La urgencia de este desafío se inscribe en un contexto de época en el que, por un lado, se vive una inusual contraofensiva de lo sensible que ha hecho del arte una pieza ineludible de la reconfiguración del espacio de lo común mientras que, por otro, el lugar clásico que antaño ocupaban el aula o el taller ha sido lentamente erosionado por una especie de nueva travesía medieval: la que cada quien cursa a su manera visitando páginas web que funcionan como verdaderas aldeas cerradas. Ambas situaciones llaman al arte a repensar su modelo de enseñanza pública. No se trata en ningún caso de anular el taller o el aula de clases, sino de incorporar estos nuevos elementos con el fin de hacer del arte un espacio privilegiado de reflexión sobre lo público en el estado de su propia metamorfosis y transformación. 